\title{
DO STUDENTS EXPERIENCE FLOW CONDITIONS ONLINE?
}

\author{
Katrina A. Meyer \\ University of Memphis \\ Stephanie J. Jones \\ Texas Tech University
}

\begin{abstract}
This pilot study asked graduate students enrolled in higher education programs at two institutions to ascertain whether and to what extent they experienced nine flow-related conditions in two settings: (1) online courses or (2) surfing or gaming online. In both settings, flow was experienced "sometimes," although no significant difference in mean frequency was found between the two settings. When asked for examples of flow, however, students gave more examples drawn from non-class-related activities $(n=$ 35) - such as researching topics related to health, travel, or shopping, or engaging with Facebook - than class-related activities $(n=3)$. Finally, students found that online class experiences "frequently" impacted their satisfaction with the course, and three flow conditions were found to be correlated with course satisfaction at $p \leq 0.05$ : clear goals, concentration and focus, and a sense of personal control over activity.
\end{abstract}

\section{KEYWORDS}

Online learning, flow, graduate students, higher education

\section{INTRODUCTION}

When Mihaly Csikszentmihalyi [1] published the results of his research on "optimal experiences," the word "flow" became part of society's vernacular for those moments when individuals are pursuing an activity that challenges and involves them to such an extent that the experience of time passing is lost. Not surprisingly, researchers in psychology and other fields began to investigate this concept further, as did Csikszentmihalyi [2, 3, 4]. It did not take long for researchers to ask whether flow could be experienced while using a computer, and then to ask if flow could be experienced by students pursuing online learning, which is the focus of this study. More specifically, this study explores whether graduate students experience flow conditions in their online courses or other, non-class-related but online activities.

\section{REVIEW OF LITERATURE}

\section{A. Flow Defined}

In Csikszentmihalyi, flow is a psychological theory that describes a peak or optimal personal experience [1]. It has been conceptualized as requiring nine conditions to occur: a balance of 1) challenge and 2) skills on the part of the individual, a 3) merging of action and awareness, 4) clear goals and 5) relevant feedback, 6) concentration and 7) the possibility of control, creating 8) the loss of self-consciousness and 9) transformation (either speeding up or slowing) of time. This research focuses on these nine conditions. The theory of flow posits that "flow" experience requires that the individual achieve an "autotelic" experience, which happens when a self-contained activity is done for no reward "because the doing itself is the reward" [1, p. 67]. The "flow channel" is conceptualized as an optimal combination of challenges 
and skills, which balance in such a way that the participant avoids experiencing too much anxiety or boredom.

\section{B. Work or Computers and Flow}

Early research studies on flow tended to focus on individuals' work or leisure experiences, and then evolved to studies of flow while individuals used a computer or the web. Csikszentmihalyi and LeFevre began this trend of flow research by studying adult workers at three levels (clerical, blue-collar, and manager) and found that flow seemed to occur predominantly in work-related activities rather than in leisure-related activities (primarily watching TV) [5]. Other researchers combined these topics and investigated playfulness as a component of flow and its positive and negative consequences on work [6]. Furthermore, when the flow experience of consumers using the web was investigated [7], both taskoriented and experiential activities were found to produce flow. Another study [8] looked at flow for two high school students and proposed flow as occurring within Vygotsky's "zone of proximal development" [9], in which the individual is ready for learning, and that "futility" was the opposite condition of flow. In a study of flow among students creating an educational game, it was found that content construction was the optimal flow-producing stage [10]. If one issue predominates in this research, it is the focus on the type of activity producing flow (i.e., work or leisure; task or experiential) and specific activities (e.g., content construction) or personal conditions (readiness for learning) that produce flow.

An example of a study that undertook an examination of the multidimensionality of the flow construct in the computer-mediated environment included a complex conceptualization and modeling of flow [11]; however, the current study described here chose a much simpler approach to identifying flow. Another attempt to create a structural model to capture the role of flow experiences on consumer shopping behaviors that occur online was notable for its extensive review of various instruments that have been used to assess flow [12], which is an issue that will be taken up again when the issue of instrument design is discussed.

\section{Online Education and Flow}

Online education has exploded in recent decades, as witnessed by growth in enrollments from 937,000 students in 2004 [13] to 1.2 million students in 2005 and to 3.9 million, or 7.9 percent of the total student enrollment in degree-granting institutions, in 2007 [14]. Enrollments in online courses totaled 6.1 million students in fall 2011 [14]. In addition, 20\% of students surveyed took an online course in 2007 [13], and one-third took an online course in 2011 [15]. Faculty and higher education institutions responded to students" interest in online "anytime, anywhere" learning so that in 2011, 65\% of institutions nationwide believed online learning to be critical for their long-term growth or stability [15]. This growth of enrollments and programs justifies research into the experiences of these millions of online students, and makes one wonder if flow experiences may be occurring for them.

But in its early permutations, the online course was often passive, relying on the student's willingness to read copious amounts of text online. As courses evolved, the focus soon became not just the provision of content, but also engaging more of the learner's skills and providing more challenges for the learner to resolve. Several studies, which by no means provide a comprehensive view of flow in online or computermediated learning, have been conducted and are worth a more detailed review.

For instance, in a study of flow's impact on learning, flow did not predict learning performance [16]; however, the flow measure did predict the student's perceived learning of the subject matter in the online course. This interesting finding makes one wonder if flow causes students to perceive they have learned, even if their learning was not that which was prescribed by the faculty person. In another study, both direct and indirect impact of flow on learning outcomes were found [17]; in this particular structural model, the flow experience loaded $0.296(p<0.01)$ on learning outcomes and $0.238(p<0.01)$ on the student's attitude toward e-learning. Further research looked at the impact of "learning flow" on student persistence and found that the presence of learning flow loaded $0.705(p=0.001)$ into a corrected model of learning persistence in these online courses [18]. The model also included measures of internal locus of 
control $(0.333, p=0.05)$ and institutional support (which did not significantly impact persistence); learning flow appeared to have the greatest influence of all of the variables on persistence in this model for online learning. These studies give a sense of the kinds of research needed to flesh out the relationship between flow and educational outcomes of interest in higher education; they by no means answer the question of flow's existence or impact on student online learning in any comprehensive or conclusive manner.

In further studies, student experiences of flow were tied to their satisfaction with the online course [16, 19]. When a multiple regression was calculated for all demographic and flow variables, a correlation of $0.662(p<0.01)$ between flow and satisfaction was produced - the highest correlation of all of the variables in the study [19]. Flow was a significant predictor of student satisfaction, with two flow conditions - perceived balance of challenge and skills as well as feedback-being significant predictors of flow's impact on student satisfaction [16]. The current research includes an analysis of the role of flow on a student's satisfaction with his or her online courses.

Research on the theory of flow in online learning is still infrequent and leaves many gaps in the field. Prior research has focused on undergraduate students, so the question of whether flow occurs in the graduate online course remains to be answered. Are adult students experiencing flow in their noneducation online experiences (such as online games)? It is not precisely clear from this research what is happening with the individual when flow is experienced. And the research on course satisfaction and the experience of flow certainly needs to be studied in other populations, such as adult graduate students.

\section{Research Questions}

Based on the literature review that has been presented, five research questions were developed to explore whether graduate students in online courses and other online settings experienced the nine flow conditions and to what extent they were experienced. Since this research may be one of the first to explore these issues with graduate students, any findings will need to be confirmed by further research. The five questions developed are the following:

1. How often do graduate students in online courses experience flow conditions?

2. How often do graduate students doing non-class-related online activities experience flow conditions?

3. Are there differences in the frequency of flow conditions between the two settings (online courses versus non-course-related online activities)?

4. In what kinds of activities do students experience flow conditions?

5. Is there a relationship between flow conditions and satisfaction with online coursework?

\section{METHODOLOGY}

\section{A. Research Design}

A survey research design was chosen for this study to begin to explore the incidence and frequency of flow for students taking courses online and participating in online activities that are not class related. It used Likert-style ratings about frequency of occurrence of specific flow conditions as well as an openended question to elicit students' examples of flow experiences, which was analyzed using qualitative coding. It is considered to be a pilot study that can form the basis for additional studies that delve into this phenomenon in more depth.

\section{B. Research Settings}

This research draws upon the students enrolled in two graduate-level programs in higher education. Because it was important to ensure that students had extensive experiences with online learning, it was decided to focus on students enrolled in primarily online or heavily blended courses or programs at the doctoral level. While online doctoral programs are not common, two such comparable programs were found that could be accessed conveniently by the researchers. One institution offers four graduate-level 
programs: a blended $\mathrm{EdD}$ and $\mathrm{PhD}$ in higher education, an online EdD program in higher education with a community college administration emphasis, and a blended Master's of Education in Higher Education and Student Affairs. The program defines blended as meaning that one or more classes can be taken through distance technologies. In any case, all students have experienced a fully online course in their degree programs and so are suitable for inclusion in this study. The other institution offers three graduatelevel programs online: a Master of Science in Leadership and two EdD programs in Adult Education and in Higher Education. While the institutions are different in some ways, they also share similarities. Both are large, publically supported research institutions offering degrees at the undergraduate and graduate levels. Both universities' higher education programs enroll primarily adult, working professionals, many of whom work full-time in positions within higher education institutions. Both are developing online programs to serve a larger regional student population. The online courses at both institutions were fully asynchronous courses at the time of this study.

\section{Sample and Population}

During fall 2011, when this research was conducted, the population of graduate students in the online and blended graduate programs at both institutions totaled 172 students. Although all students were asked to participate in the study, the final sample included responses from 67 students for a combined 39\% response rate. Table 1 presents a profile of the sample in comparison to the population of both programs together based on gender and ethnicity.

\begin{tabular}{|l|c|c|c|c|}
\hline & \multicolumn{3}{|c|}{ Sample } & \multicolumn{2}{c|}{ Population } \\
\hline Gender & 42 & $62.6 \%$ & 94 & $55.0 \%$ \\
\hline Female & 25 & $37.3 \%$ & 77 & $45.0 \%$ \\
\hline Male & 7 & $10.4 \%$ & 34 & $19.8 \%$ \\
\hline Ethnicity & 2 & $3.0 \%$ & 2 & $1.2 \%$ \\
\hline African American & 2 & $3.0 \%$ & 16 & $9.3 \%$ \\
\hline Asian & 56 & $83.6 \%$ & 120 & $69.8 \%$ \\
\hline Hispanic*
\end{tabular}

*Includes Latino, Mexican-American, etc.

Table 1. Sample versus population in fall 2011

In addition, the students ranged in age from 20-29 (23.5\%), 30-39 (35.3\%), 40-49 (23.5\%), to 50+ (17.6\%), placing the sample clearly within the adult student category. Based on the data on gender and ethnicity, the sample was $7.6 \%$ more female and $13.8 \%$ more Caucasian than the population of the programs. Therefore, based on the profile in Table 1, the sample is relatively representative of the population of students admitted to these graduate programs.

The Institutional Review Boards of both institutions granted approval to conduct this research. Because the research used SurveyMonkey.com for collecting the data and no identifying information was collected in the survey, individuals in the sample were assured anonymity.

\section{Instrument Development}

Three demographic questions (regarding gender, age in 10-year periods, and race/ethnicity) were included in the instrument for the sole purpose of assessing whether the final sample was an accurate representation of the population. Then, prior to the research being initiated, instruments used in prior research were reviewed for possible adoption in this study. However, many of these had multiple items that would prove difficult to justify in an online survey intended to serve many research ends and might seem - due to the length of the instrument and the time required to complete it - unattractive or too demanding to students. For these reasons, depth of the constructs with multiple items for each flow condition was sacrificed, and single items for each flow condition were used for a simpler instrument that would appeal to (and be completed by) more students. This decision, as reasonable as it seemed to the authors, makes the results less comparable to those of other studies on flow. 
To develop the instrument, several items were brainstormed for inclusion based on multiple readings of the literature - especially the first work on flow referred to earlier [1] — on the nine conditions for flow to occur. These items asked students to assess the extent to which the following nine conditions described their experiences when they were online and engaged in either class or non-class activities:

- clear goals;

- concentration and focus;

- a loss of self-consciousness;

- distorted sense of time (time stands still or flies by);

- direct and immediate feedback;

- balance between ability and challenge (the activity is neither too easy nor too difficult);

- a sense of personal control over activity is possible;

- activity is intrinsically rewarding; and

- absorption in the activity.

Because one focus of the research was assessing the frequency with which flow conditions occurred, all items were assessed by a Likert-style scale, with the descriptors (and codes) being coded as follows: "not at all" coded as one, "rarely" coded as two, "sometimes" coded as three, "frequently" coded as four, and "all of the time" coded as five. Likert-style items were common among the instruments reviewed for this study and were used in most of the studies reviewed earlier. This allowed both a mean frequency to be calculated and the frequency of responses to be reported.

In order to assess whether students had experienced the nine flow conditions online and the extent to which flow conditions occurred, students were asked to answer based on two settings: (1) participating in an online class, (2) or surfing or gaming online. Inclusion of the surfing or gaming experience was an attempt to compare an intentional educational setting (the online class) with a more playful setting, which was the focus of prior research $[6,10]$. These settings were chosen in an attempt to explore differences (if any) between flow conditions occurring when individuals were online for a class or for out-of-class activities; these two settings are comparable to the work-versus-leisure settings of the previously mentioned research [5].

A third question was left open ended and asked students to "Describe a time when you experienced a loss of time and self while working online. What were you doing?" Posing the question in an open-ended way was done to allow students to contribute what they thought were their own flow-like experiences, which would be intrinsically interesting but also provide insight into the question of whether flow experiences happened more frequently in class or out of class, in work or leisure settings. Asking such a question about events occurring some time in the past can be justified by the findings of prior research done by Rossin et al. [16]. Their study specifically looked at the study participants' recall of flow events and, perhaps due to flow's memorable qualities, found that participants had no difficulty recalling flow even when it had occurred days, weeks, or months earlier.

A final question asked students how often they were satisfied with their online courses, using the same five Likert-scale labels coded one through five, as above.

A draft version of the instrument was then pilot-tested with three graduate students who were asked to complete the instrument but also to identify questions that were not clear or confusing. A revision of the instrument was undertaken at this stage to address slight word changes or areas of clarifications mentioned by these reviewers. The instrument was created within the SurveyMonkey.com site and was reviewed for accuracy and readability by the second author of this paper.

Given that both the pilot test $(n=3)$ and the sample $(n=67)$ are small in size, interpretations derived from the use of this instrument should be made with caution until further replication studies - with larger samples - can be undertaken.

\section{E. Data Collection}


Both institutions that participated in this study create e-mail listservs comprised of all students admitted into a degree program, which are used by faculty and/or administrators wishing to communicate to all students; these e-mail programs are available to each author for the institution at which each is located. In early September 2011, e-mails were sent by the authors inviting students enrolled in their institution's programs to participate in the study and providing them with the link to the SurveyMonkey site. After two weeks, a follow-up e-mail was sent to thank individuals who had completed the survey and to invite remaining students to participate in the study; this e-mail also provided a deadline of one week thereafter for completing the survey.

Once the SurveyMonkey site was closed, data were downloaded and printed for analysis. Data were also imported into SPSS version 14 for statistical analysis to answer research questions 3 and 5.

\section{F. Data Analysis}

Research question 1, "How often do graduate students in online courses experience flow conditions?" was answered by reporting the frequency and means of the nine items capturing the flow conditions.

Research question 2, "How often do graduate students doing non-class-related online activities experience flow conditions?" was answered by reporting the frequency and means of the same nine flow items above, but applied to surfing and gaming activities online.

Research question 3, "Are there differences in the frequency of flow conditions between the two settings (online courses versus non-course-related but online activities)?" was answered by calculating the mean responses for each flow condition and each setting (within class and out of class) and calculating $t$-tests for comparison of the means. Given the small sample, a $p$ value of 0.05 was chosen for determining a significant difference.

Research question 4, "In what kinds of activities do students experience flow conditions?" was analyzed by coding the student responses to the open-ended question and determining similarity of codes as well as possible themes for those codes; inconsistencies were noted, and explanations in light of the previous literature are proposed.

Research question 5, "Is there a relationship between flow conditions and student satisfaction with online coursework?" was answered by calculating the correlation and variation explained $\left(r^{2}\right)$ for each flow element in the question about flow in online courses (Table 2) and student satisfaction in the course (Table 5). Because the flow conditions and the course satisfaction variables were all in Likert scale and coded one through five, this is an imperfect use of correlation, because Likert-scale data are considered to be ordinal rather than interval data. However, the use of ordinal data with ANOVA and other intervalscale statistics has been supported [20], because ordinal data are often treated as interval data by subjects and researchers alike.

\section{G. Assumptions and Limitations}

The validity of survey research depends on several assumptions. First, it is assumed that participants in the survey answered honestly and did not attempt to answer as they thought they ought to. Given that the survey was sent out to all graduate students enrolled in the stated programs at both universities, the likelihood that participants responded as if a course grade would be affected is minimized, and the anonymity assured by using SurveyMonkey would ensure their responses could not be identified as their own. Second, it is assumed that participants can reflect on and remember their experiences while online, even if what happened may be days or weeks in the past. Given the earlier research [16], in which subjects had no trouble remembering flow experiences that had occurred some time in the past, this seems a sensible assumption. Third, it is assumed that participants are sufficiently self-aware to recognize their own subjective experiences and to do so accurately, even if they would not use the particular terminology of flow to describe these. 
This research has two limitations. First, as noted earlier, the instrument requires further testing on larger samples. Second, the findings may not be generalizable to graduate students at other universities, undergraduate students, or students in other, more traditionally delivered educational programs.

\section{RESULTS}

In answer to research question 1, "How often do graduate students in online courses experience flow conditions?" students indicated how frequently they experienced flow conditions in their online courses. Table 2 presents these results broken down into frequency category (never, rarely, sometimes, frequently, all of the time) and gives the mean for the flow condition. What is intriguing in these results is the relative consistency among means; all nine items seem to be experienced "sometimes," with the first two items ("clear goals," "concentration and focus") almost reaching the level of happening "frequently." In other words, these students are experiencing some flow conditions in their online classes at least sometimes.

\begin{tabular}{|l|c|c|c|c|c|c|}
\hline Flow condition & Never & Rarely & Sometimes & Frequently & $\begin{array}{c}\text { All of the } \\
\text { time }\end{array}$ & $\mathrm{M}$ \\
\hline Clear goals & $0.0 \%$ & $7.0 \%$ & $17.5 \%$ & $63.2 \%$ & $12.3 \%$ & 3.80 \\
\hline Concentration and focus & $0.0 \%$ & $5.4 \%$ & $23.2 \%$ & $57.1 \%$ & $14.3 \%$ & 3.80 \\
\hline $\begin{array}{l}\text { A loss of self- } \\
\text { consciousness }\end{array}$ & $14.3 \%$ & $35.7 \%$ & $32.1 \%$ & $16.1 \%$ & $1.8 \%$ & 2.55 \\
\hline $\begin{array}{l}\text { Distorted sense of time } \\
\text { (time stands still or flies } \\
\text { by) }\end{array}$ & $7.0 \%$ & $26.3 \%$ & $47.4 \%$ & $17.5 \%$ & $1.8 \%$ & 2.81 \\
\hline $\begin{array}{l}\text { I get direct and } \\
\text { immediate feedback }\end{array}$ & $3.5 \%$ & $31.6 \%$ & $52.6 \%$ & $10.5 \%$ & $1.8 \%$ & 2.75 \\
\hline $\begin{array}{l}\text { Balance between ability } \\
\text { and challenge* }\end{array}$ & $0.0 \%$ & $5.3 \%$ & $56.1 \%$ & $33.3 \%$ & $5.3 \%$ & 3.39 \\
\hline $\begin{array}{l}\text { A sense of personal } \\
\text { control over activity }\end{array}$ & $1.8 \%$ & $14.0 \%$ & $33.3 \%$ & $43.9 \%$ & $7.0 \%$ & 3.40 \\
\hline $\begin{array}{l}\text { Activity is intrinsically } \\
\text { rewarding }\end{array}$ & $0.0 \%$ & $28.1 \%$ & $43.9 \%$ & $22.8 \%$ & $5.3 \%$ & 3.05 \\
\hline $\begin{array}{l}\text { I am absorbed in the } \\
\text { activity }\end{array}$ & $3.5 \%$ & $26.3 \%$ & $35.1 \%$ & $26.3 \%$ & $8.8 \%$ & 3.11 \\
\hline
\end{tabular}

*The activity is neither too easy nor too difficult.

Table 2. Frequency of occurrence while in online class $(n=57)$

For research question 2, "How often do graduate students doing non-class-related online activities experience flow conditions?" students indicated how frequently they experienced flow conditions while surfing or gaming online. Table 3 presents these results broken down into frequency category ("never," "rarely," "sometimes," "frequently," "all of the time") and provides the mean for the flow condition. As with the means for the in-class setting, all of these means fall into the "sometimes" category, with two conditions ("a sense of personal control over activity" and "I am absorbed in the activity") nearing the "frequently" level. In other words, these students are experiencing flow conditions in their online out-ofclass activities.

\begin{tabular}{|l|c|c|c|c|c|c|}
\hline Flow condition & Never & Rarely & Sometimes & Frequently & $\begin{array}{c}\text { All of the } \\
\text { time }\end{array}$ & $\mathrm{M}$ \\
\hline Clear goals & $1.8 \%$ & $19.3 \%$ & $33.3 \%$ & $33.3 \%$ & $12.3 \%$ & 3.35 \\
\hline Concentration and focus & $1.8 \%$ & $5.3 \%$ & $35.1 \%$ & $49.1 \%$ & $8.8 \%$ & 3.58 \\
\hline A loss of self- & $10.5 \%$ & $15.8 \%$ & $52.6 \%$ & $17.5 \%$ & $3.5 \%$ & 2.88 \\
\hline
\end{tabular}




\begin{tabular}{|l|c|c|c|c|c|c|}
\hline consciousness & & & & & & \\
\hline $\begin{array}{l}\text { Distorted sense of time } \\
\text { (time stands still or flies } \\
\text { by) }\end{array}$ & $5.3 \%$ & $12.3 \%$ & $33.3 \%$ & $38.6 \%$ & $10.5 \%$ & 3.37 \\
\hline $\begin{array}{l}\text { I get direct and immediate } \\
\text { feedback. }\end{array}$ & $3.5 \%$ & $14.0 \%$ & $52.6 \%$ & $26.3 \%$ & $3.5 \%$ & 3.12 \\
\hline $\begin{array}{l}\text { Balance between ability } \\
\text { and challenge* }\end{array}$ & $1.8 \%$ & $10.5 \%$ & $45.6 \%$ & $35.1 \%$ & $7.0 \%$ & 3.35 \\
\hline $\begin{array}{l}\text { A sense of personal control } \\
\text { over activity }\end{array}$ & $1.8 \%$ & $1.8 \%$ & $24.6 \%$ & $47.4 \%$ & $24.6 \%$ & 3.91 \\
\hline $\begin{array}{l}\text { Activity is intrinsically } \\
\text { rewarding }\end{array}$ & $1.8 \%$ & $7.1 \%$ & $41.1 \%$ & $39.3 \%$ & $10.7 \%$ & 3.50 \\
\hline $\begin{array}{l}\text { I am absorbed in the } \\
\text { activity. }\end{array}$ & $1.8 \%$ & $1.8 \%$ & $38.6 \%$ & $43.9 \%$ & $14.0 \%$ & 3.67 \\
\hline
\end{tabular}

*The activity is neither too easy nor too difficult.

Table 3. Frequency of occurrence while surfing or gaming $(n=57)$

In answer to research question 3, "Are there differences in the frequency of flow conditions between the two settings (online courses versus non-course-related but online activities)?" the means of each flow item for the two settings were compared by a correlated samples $t$-test. At first glance, the means might seem different, with higher means for "clear goals" and "concentration and focus" in online classes. (Given the structured and goal-directed activity of an online class, higher means for these two flow conditions seem to make sense.) For all other flow conditions, the means while performing the out-ofclass activities of surfing or gaming were higher. This increase means that activities done more for fun or out of personal interest seem to create a higher frequency of flow conditions. However, based on the $t$ test, the means were not significantly different $(t(8)=0.9, p=0.197)$. Therefore, it is concluded that students experience flow conditions at similar rates while in the two online settings.

In answer to research question 4, "In what kinds of activities do students experience flow conditions?" the 38 examples given by students seem to augment-and dispute - the results in Tables 2 and 3. Three examples $(8 \%)$ were clearly class or program related (i.e., working on the dissertation), with an additional 14 examples $(37 \%)$ focused on either their jobs or professional obligations $(n=5)$ or research conducted for personal or family reasons $(n=9)$. This latter category was intriguing, and included using the Internet to plan travel, looking up family or genealogical information, researching medical treatments, reading reviews about a product before purchasing, researching gardening sites, and investigating houses and neighborhoods. For example, one flow example was "I was researching a product that I assumed would only take a few minutes. I kept finding more information, reviews, etc. Before long, my few minutes translated into 90 minutes. I had no idea it had taken so much time." Gaming $(n=3)$ and surfing $(n=2)$ were also mentioned, as were shopping $(n=3)$; this gamer provides a good example of this category of responses:

Once during the summer I was playing a game online - one of those hidden object games that are a mixture of strategy and mystery-simply as a stress-reliever, and one hour later, was still playing! I lost all sense of time. It felt awful and good at the same time. Good, because it helped to relieve stress, but I felt guilty because I thought of all the things I could have been doing that were more productive!

However, another 13 examples (34\%) described experiencing flow while on Facebook $(n=9)$ and pinterest.com $(n=4)$, a website where people post things they love and want to share with others. In other words, these students experienced flow most often while using the Internet to address personal interests (be it keeping up with family, researching information, or just enjoying themselves). One student stated the following: 
I was working on a project that required focus, as I was learning a new skill. I found enough success in completing it and more challenge online to keep me going. I was learning how to link various social media accounts and make sure domains were leading to correct places.

In other words, some of these students clearly seemed to experience what they considered to be flow, but it was more likely to happen while pursuing their own interests rather than an instructor's. Their interests, however, were often oriented to finding important information, such as cancer treatments for a relative. This information seems to dispute the frequency of occurrence of flow in Table 2 that captured flow conditions occurring in online courses; on the other hand, perhaps students' out-of-class flow experiences came more quickly to mind when they were asked to provide an example. In any case, this is an issue that requires further exploration.

To answer the question about the relationship of the nine flow conditions to course satisfaction, Table 4 provides the raw data on course satisfaction, which confirms that students' online class experiences frequently $(M=3.9)$ impact their satisfaction with the course. Then correlation $\left(r^{2}\right)$ was calculated for each of the nine flow conditions in the online course condition against the frequency results for satisfaction with course. Table 5 presents the $r^{2}$ calculations for each flow element against the course satisfaction data.

\begin{tabular}{|l|l|l|l|l|l|l|}
\hline Activity & Never & Rarely & Sometimes & Frequently & $\begin{array}{l}\text { All of the } \\
\text { time }\end{array}$ & M \\
\hline Satisfaction with course & $0.0 \%$ & $8.9 \%$ & $19.6 \%$ & $46.4 \%$ & $25.0 \%$ & 3.9 \\
\hline
\end{tabular}

Table 4. The impact of online class experiences $(n=57)$

\begin{tabular}{|l|c|}
\hline Flow condition & $r^{2}$ \\
\hline Clear goals & $.871^{* *}$ \\
\hline Concentration and focus & $.903^{* *}$ \\
\hline A loss of self-consciousness & .070 \\
\hline Distorted sense of time (time stands still or flies by) & .000 \\
\hline I get direct and immediate feedback. & .010 \\
\hline Balance between ability and challenge* & .237 \\
\hline A sense of personal control over activity & $.614^{* * *}$ \\
\hline Activity is intrinsically rewarding & .058 \\
\hline I am absorbed in the activity. & .151 \\
\hline
\end{tabular}

$*$ The activity is neither too easy nor too difficult.

$* * p<0.05$

$* * * p=0.05$

Table 5. Correlations of flow conditions with course satisfaction

What is of interest in the correlations in Table 6 are the three flow conditions that appear to somewhat explain the variance in course satisfaction: clear goals $\left(r^{2}=.87\right)$, concentration and focus $\left(r^{2}=.90\right)$, and a sense of personal control over activity $\left(r^{2}=.61\right)$. While the first two make sense as elements of formal instruction, the third is intriguing and may capture the importance to students of exercising some control or influence over the course's activities. This is supported by adult learning theory, which supports the adult student learner's self-concept and need for self-direction. These findings are clearly tentative and require more extensive investigation to discover why the other flow conditions may have less of a role in course satisfaction, if individual differences can be found, or whether other variables affect these relationships. In the interim, however, those who design online courses may wish to make use of these findings by implementing clear goals, offering individualized opportunities for concentration and focus, as well as personal control over the learning task or learning objectives.

\section{DISCUSSION AND FUTURE RESEARCH}


This section will focus on implications from these findings and the research questions that must be addressed next to extend the field's understanding of flow theory in the experiences of online student learning. Based on these results, it can be tentatively concluded that flow conditions were experienced by students in these online classes at least "sometimes." This result confirms that flow conditions can and do occur in these online classes $[18,19]$. And if they do occur, two questions deserve further exploration in subsequent research. First, was the flow experience something that was triggered by the course design, the course content, by a task set by the instructor, an interaction with a fellow student, or something else entirely? If flow is something worthwhile, or even something that makes the online learning experience more enjoyable, researchers and online instructors need to explore how to bring it about in a more purposeful and intentional way. The second question focuses on the relationship between frequency of occurrence and learning outcomes. Is a higher frequency of occurrence for flow tied to better learning or more learning, to learning sought by the instructor, or only learning that is tertiary to the course objectives?

While flow conditions also did occur while students were gaming or surfing online, in no case were the means for frequency of occurrence between the two settings (in class, out of class) significantly different. This finding confirms earlier research that focused on flow in both work and leisure situations and found that flow occurred during both types of activities [10]. This finding raises two additional questions: Are the experiences of flow in the two settings different from each other in some fashion, and do flow experiences in non-class-related settings influence student expectations for finding flow in their online courses? In other words, researchers may need to explore whether ways can be found to maximize students' out-of-class flow experience for the purposes of advancing traditional educational goals, such as student learning.

However, flow does not occur equally in work and leisure activities, as might be implied by earlier research [10]. Based on the examples of flow given by the students, it was clear that most of the instances cited were not class related. Is this absence of the experience of flow due to a lack of appropriate course design, or can course design overcome the fact that courses may not always be intrinsically interesting to all students? Finally, given the extent to which these students used online venues to pursue their own research for family information, travel planning, or even meal planning, perhaps online instructors can find ways to bring students' interests into coursework so that flow is more likely to occur.

Finally, flow did appear to be related to course satisfaction, as earlier studies implied [16, 19]. Can this relationship be maximized so that more flow leads to greater satisfaction, or could this relationship be tempered by other factors, such as grades, the level of student (undergraduate and graduate), or personality factors? There is much to be done to flesh out this relationship and explore how and when it occurs.

So far, it appears there are more questions than answers. Given the still nascent state of flow research and online learning, this uncertainty should not be surprising, but should confirm that this concept of flow and online learning deserves further study. Of course, the survey instrument needs further testing as well, and the questions initiated herein need to be asked of students of different ages, programs of study, and locations. Researchers are by no means at the end of the research of flow, for flow research may be an opportunity for flow to be experienced by researchers who are fascinated by what makes it happen and how to design online coursework so flow can be a frequent experience of students.

\section{REFERENCES}

1. Csikszentmihalyi, M. Flow: The Psychology of Optimal Experience. New York: Harper and Row, 1990. 
2. Csikszentmihalyi, M. The Evolving Self: A Psychology for the Third Millennium. New York: HarperCollins, 1993.

3. Csikszentmihalyi, M. Finding Flow: The Psychology of Engagement with Everyday Life. New York: Basic Books, 1997.

4. Csikszentmihalyi, M. Beyond Boredom and Anxiety: Experiencing Flow in Work and Play. San Francisco: Jossey-Bass, 2000.

5. Csikszentmihalyi, M. and LeFevre, J. Optimal Experience in Work and Leisure. Journal of Personality and Social Psychology 56(5): 815-822 (1989).

6. Webster, J., Trevino, L. K., and Ryan, L. The Dimensionality and Correlates of Flow in HumanComputer Interactions. Computers in Human Behavior 9(4): 411-426 (1993).

7. Novak, T. P., Hoffman, D. L., and Duhachek, A. The Influence of Goal-Directed and Experiential Activities on Online Flow Experiences. Journal of Consumer Psychology 13(1 \& 2): 3-16 (2003).

8. Brockberg, K. H. One-Liners: Two Case Studies of Flow and Futility. Teaching \& Learning 20(2): 132-149 (2006).

9. Vygotsky, L. Thought and Language. Cambridge, MA: The MIT Press, 1986.

10. Kiili, K. Content Creation Challenges and Flow Experience in Educational Games: The IT-Emperor Case. Internet and Higher Education 8: 183-198 (2005).

11. Siekpe, J. S. An Examination of the Multidimensionality of Flow Construct in a ComputerMediated Environment. Journal of Electronic Commerce Research 6(1): 31-43 (2005).

12. Novak, T. P., Hoffman, D. L., and Yung, Y. Measuring the Customer Experience in Online Environments: A Structural Modeling Approach. Marketing Science 19(1): 22-42 (2000).

13. Carnevale, D. Online Courses Continue to Grow Dramatically, Enrolling Nearly 1 Million, Report Says. Chronicle of Higher Education, June 28, 2005.

14. Allen, I. E., and Seaman, J. Staying the Course: Online Education in the United States, 2008. Needham, MA: Sloan-C, 2008.

15. Allen, I. E., and Seaman, J. Going the Distance: Online Education in the United States, 2011. Needham, MA: Sloan-C, 2011.

16. Rossin, D., Ro, Y. K., Klein, B. D., and Guo, Y. M. The Effects of Flow on Learning Outcomes in an Online Information Management Course. Journal of Information Systems Education 20(1): 8798 (2009).

17. Choi, D. H., Kim, J., and Kim, S. H. ERP Training with a Web-Based Electronic Learning System: The Flow Theory Perspective. International Journal of Human-Computer Studies 65: 223 243 (2007).

18. Young J. J., Joung, S., and Sim, W. J. Structural Relationships Among Internal Locus of Control, Institutional Support, Flow, and Learner Persistence in Cyber Universities. Computers in Human Behavior 27: 714-722 (2011).

19. Shin, N. Online Learner's "Flow" Experience: An Empirical Study. British Journal of Educational Technology 37(5): 705-720 (2006).

20. Simon, S. P. P.Mean: Use of Likert Data with ANOVA. Retrieved from

http://www.pmean.com/09/LikertAnova.html

\section{ABOUT THE AUTHORS}

Dr. Katrina Meyer is currently a professor of higher and adult education and coordinator of the online EdD in Higher Education program at the University of Memphis. Her research specializes in online learning and higher education, and she is the author of Lessons Learned from Virtual Universities, a 2009 publication in the New Directions in Higher Education series, and Cost-Efficiencies of Online Learning, a 2006 publication of the ASHE Higher Education Report Series. For over three years, she was Director of Distance Learning and Technology for the University and Community College System of Nevada. Prior to that, she served over eight years as Associate Director of Academic Affairs for the Higher Education Coordinating Board in the state of Washington and was responsible for technology planning and policy related to online learning. 
Dr. Stephanie J. Jones is an associate professor and program coordinator of the higher education program at Texas Tech University. She has been involved at the state level with distance learning initiatives through the Virtual College of Texas, Texas Leadership Alliance, and the Texas Higher Education Coordinating Board. Dr. Jones' research interests include community colleges, distance learning, and gender issues within working environments for women in professional roles in higher education. Dr. Jones began her career in information technology as a software developer, project manager, and database administration. 